\title{
Representaciones sociales de la inseguridad en El Salvador de la posguerra: Estudio de casos del AMSS
}

LORENA UMAÑA

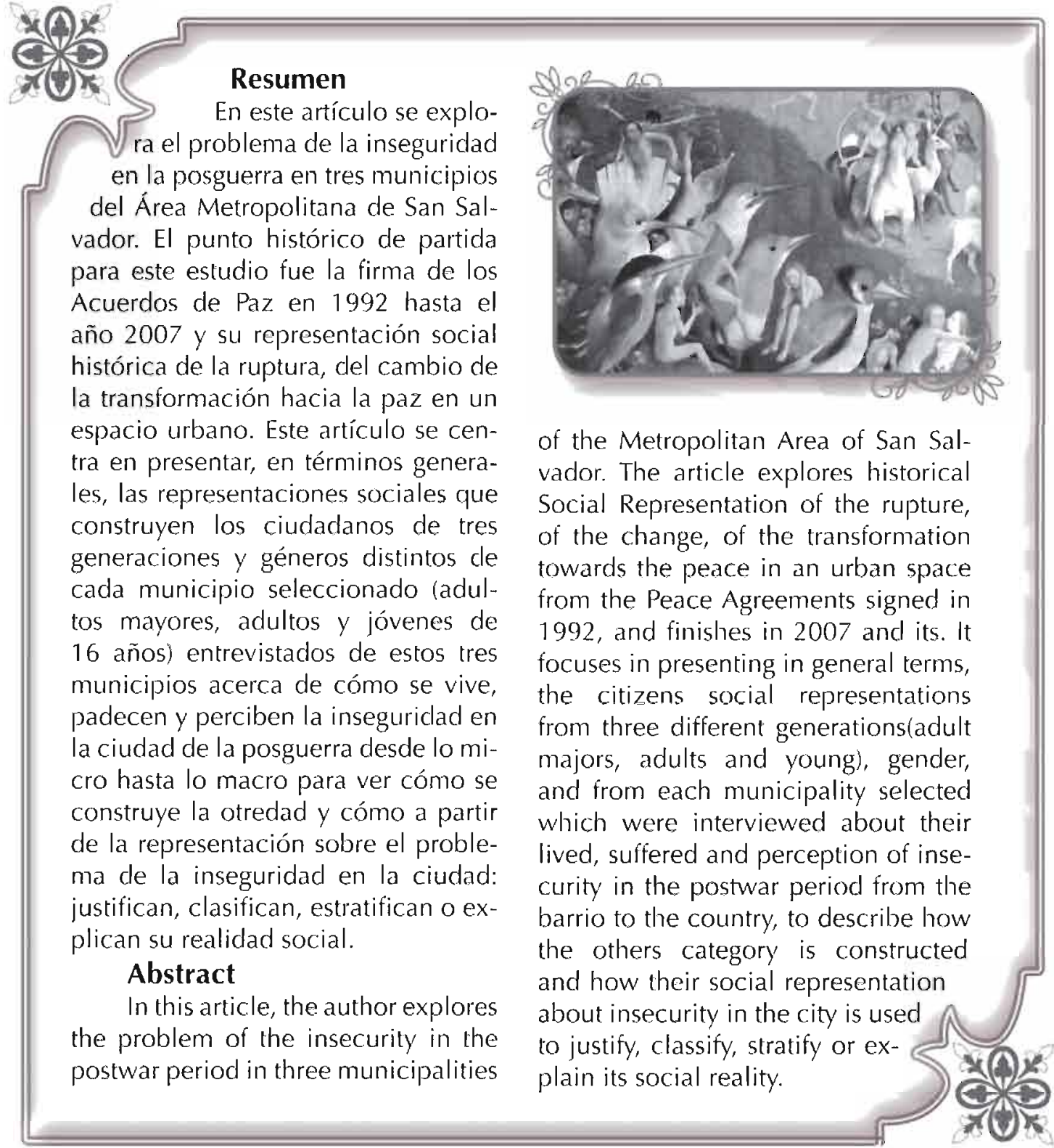


a década de los 80 fue una década convulsionada para América Latina. Muchas de las naciones centroamericanas estuvieron sometidas a guerras civiles. El Salvador, el país más pequeño de la región, con 21 mil 041 kilómetros cuadrados, y también uno de los más empobrecidos, no fue la excepción. Tras más de 11 años de guerra, este conflicto finalizó con la firma de los Acuerdos de Paz en el Castillo de Chapultepec en México, el 16 de enero de 1992. Los años de conflicto armado tuvieron como consecuencia más de 80 mil muertos, así como profundas cicatrices en la sociedad salvadoreña: estructuras institucionales y redes de relaciones sociales erosionadas en todo el país. Ante esta realidad se hizo urgente iniciar la reconstrucción del país, a todos los niveles, desde lo físico, económico y social, hasta lo simbólico y psicológico.

En la posguerra, con la firma de los Acuerdos de Paz en 1992, se inició un período de pacificación y reconstrucción. Con este nuevo período y con el primer triunfo electoral del partido de extrema derecha, se intentó retomar el proyecto de modernización, detenido durante la guerra. Se le intentó dar apertura a todos los sectores políticos y empezar un proceso de construcción de una institucionalidad, de reconstrucción territorial y de reinserción de sectores excluidos y de excombatientes. Se inició además un proceso de depuración de las Fuerzas Armadas y la Policía Nacional, la cual se transformó en Policía Nacional Civil. Se creó la Procuraduría para la Defensa de los Derechos Humanos y con la participación del Frente Farabundo Martí para la Liberación Nacional (FMLN) como partido político de izquierda se inició un nuevo período de gobiernos municipales en los que la izquierda obtuvo rotundos éxitos, como en el caso de San Salvador, hasta las elecciones de 2006.

Sin embargo, el fin de la guerra ha dejado deudas no saldadas desde el punto de vista económico. Atrajo nuevas problemáticas sociales y económicas, nuevas inseguridades y antiguas reposicionadas en los civiles: la proliferación de pandillas, el desempleo, las desigualdades, las migraciones, las bandas de crimen organizado, entre algunas, han implicado nuevas preocupaciones $y$, por consiguiente, transformaciones en las representaciones sociales acerca de la inseguridad que tiene diferencias con las de la guerra. Este es un tiempo de guerra sin guerra. Es una guerra social, que se reflejan en las prácticas urbanas sociales de los ciudadanos en torno a sus miedos e inseguridades.

El interés en el tema de la seguridad pública y seguridad ciudadana en El Salvador es creciente y una de las principales preocupaciones actuales de los salvadoreños. Sin duda hablar de inseguridad es muy amplio, por ello, para efectos de este estudio, el enfoque de la inseguridad que retomé fue el de la 
vinculación de este concepto con el de violencia, delincuencia y victimización. Dejé de lado -para efectos metodológicos y liminales- el tema de la inseguridad con el de la incertidumbre social, la pobreza y la precariedad. Retomé el concepto de Sergio García, que la define como "una cualidad de los espacios públicos y privados, que se caracteriza por la inexistencia de amenazas que socaven o supriman los bienes y derechos de las personas y en la que existen condiciones propicias para la convivencia pacífica y el desarrollo individual y colectivo de la sociedad." (García, 2002:8)

Este estudio se enmarca en el Área Metropolitana de San Salvador (AMSS) debido a que se ha transformado en el espacio -por antonomasia- en el que se entretejen diversos tejidos cuyos entramados, dejan ver sesgos que corresponden a la manera de hacer y construir una realidad social compleja, fragmentada y contradictoria, pero también una realidad que convoca y aglutina identidades, comportamientos, actitudes y prácticas sociales en torno a la inseguridad.

Ciertamente el AMSS ha cambiado cultural, política, infraestructural, social y simbólicamente. El problema es que no se están tomando en cuenta las apreciaciones que se han originado en algunos actores con el fin de la guerra, como las decepciones al sentir que la guerra no valió la pena y que las reivindicaciones anheladas nunca se dieron, el incremento de la violencia, la delincuencia, la pobreza y la idea de que la inseguridad lo invade todo. Surgen entonces las preguntas: ¿Cuáles son las representaciones sociales de la inseguridad en la posguerra en el AMSS? ¿En qué sentido se han modificado o no las representaciones sociales en la posguerra? ¿Influyen en las prácticas de los ciudadanos? Ese fue precisamente el punto de la investigación: explorar las representaciones sociales de la inseguridad en la posguerra en el Área Metropolitana de San Salvador.

Sin embargo, el AMSS tiene 14 municipios y dadas sus dimensiones y complejidades no fue posible estudiar cada caso. Para ello, elegí tres municipios ubicados de norte a sur en esta área. Estos tres municipios están geográfica, paisajística, económica e infraestructuralmente diferenciados. Pero además, se plantean como una escala de la inseguridad territorial, siendo el municipio del sur el más seguro y el municipio del norte, el más inseguro. Los tres municipios seleccionados de norte a sur fueron Soyapango, San Salvador y Antiguo Cuscatlán.

Para realizar el estudio partí del concepto de representaciones sociales definidas como "una modalidad particular del conocimiento, cuya función es la elaboración de los comportamientos y la comunicación entre los individuos. La representación es un corpus organizado de comportamientos y una de las actividades psíquicas 
gracias a las cuales los hombres hacen inteligibles la realidad física y social, se integran en un grupo o en una relación cotidiana de intercambios, libran los poderes de su imaginación"(Moscovici, 1979: 17-18). El concepto de las representaciones ha ocupado un lugar muy importante para el estudio de la cultura. Según Hall (1997:14), la representación conecta los sentidos y los lenguajes con la cultura. Representar implica materializar, hacer aparecer un objeto en lugar de otro, o también una idea que implica a un objeto o situación incluso en ausencia de ésta. Así, representar implica otorgarle un significado a lo que aparece. Es hacer presente algo con palabras, con figuras que la imaginación retiene para nombrar, clasificar y justificar situaciones que afectan al ser humano. Representar, afirma Heidegger, citado por Lefebvre (2006: 23), es colocar ante mí (ante sí) algo que uno (yo) vuelve seguro. Por tanto verdadero. ¿llusión? En cierto sentido, pero sostenida por todo el ente. La representación parte de la realidad social como insumo, como recurso para generarse, para posibilitarse. Denise Jodelet, continuando con la línea de Moscovici, afirma que las RS determinan:

"La manera en que nosotros sujetos sociales aprehendemos los acontecimientos de la vida diaria, las características de nuestro medio ambiente, las informaciones que en él circulan, a las personas de nuestro entorno próximo o lejano. En pocas palabras el conocimien- to 'espontáneo', ingenuo (...) que habitualmente se denomina conocimiento de sentido común o bien pensamiento natural por oposición al pensamiento científico. Este conocimiento se constituye a partir de nuestras experiencias, pero también de las informaciones, conocimientos y modelos de pensamiento que recibimos y transmitimos a través de la tradición, la educación y la comunicación social. De este modo, ese conocimiento es en muchos aspectos un conocimiento socialmente elaborado y compartido. Bajo sus múltiples aspectos intenta dominar esencialmente nuestro entorno, comprender y explicar los hechos $e$ ideas que pueblan nuestro universo de vida o que surgen en él, actuar sobre y con otras personas, situarnos respecto a ellas, responder a las preguntas que nos plantea el mundo, saber lo que significan los descubrimientos de la ciencia y el devenir histórico para la conducta de nuestra vida, etc." (Jodelet, 1984:473).

Sin embargo, ese conocimiento "espontáneo" no se refiere al aparecimiento que entraña un hecho que se produce aparentemente sin causa y que, de hecho, es sinónimo del impulso. Una representación social surge ante una o unas motivaciones o una necesidad social que es causa del aparecimiento de la representación social, que probablemente surja sin una planificación rigurosa apelando al sentido común. Espontáneo, en el sentido de la apertura que se propicia por las subjetivi- 
dades sociales que generan dicha representación. En este concepto deben estudiarse por lo tanto dos niveles, el figurativo y el simbólico, ya que según Robert Farr, citado por Mora (2002: 7), las representaciones sociales tienen una doble función: "hacer que lo extraño resulte familiar y lo invisible, perceptible". Por lo tanto, deben ser instaladas en el habitus de la persona, en su cotidianidad. Las representaciones colectivas necesitan cierto grado de institucionalización u objetivación, o tipificación o rutinización o bien, como afirma Berian (1990), necesitan de un proceso de estructuración institucional que agrupe tanto al saber social como a la actividad performativa. Por ello la vinculación y la relación entre las representaciones y las prácticas sociales. No solo interesa la representación en sí, sino los efectos en la manera de hacer las cosas; de vivir, de usar la ciudad e incluso de nombrarla y dividirla, a través de las prácticas concretas. Hay que anotar que las representaciones sociales son un conocimiento que se elabora socialmente y que como tal se comparte, se legitima y se instituye pero que parte de la experiencia personal y de la información particular que cada individuo recoge de su entorno y de su historia. Esto, por lo tanto, nos lleva a pensar además en el carácter cultural de las (R.S), ya que implica un repertorio de significados compartidos, que permiten identificar a ciertos grupos y diferenciarlos de otros a través de sus prácticas cotidianas y establecer relaciones de alteridad.

El objetivo fue estudiar, a través de una investigación exploratoria y la selección de estudios de casos, las representaciones sociales de la inseguridad en la posguerra para identificar si existe una influencia de las representaciones sobre las prácticas o no. Pero también para descubrir si dichas representaciones buscan aproximarse a una ciudad ideal, deseada y mejor $y$, en rechazo, alejarse de esa ciudad en la que se ubica la otredad. Todas esas representaciones aparecen para ordenar el mundo, clasificarlo, dividirlo, diferenciarlo, entenderlo, pero también para asegurar la estabilidad social para garantizar el espacio tópico (propio) y aproximarse al espacio utópico (ideal) en contraposición y rechazo a aquel espacio heterotópico (ajeno, amenazante), indeseado pero tan necesario para el mantenimiento del orden social.

La investigación no pretendió enmarcarse en una línea cuantitativa, ni pretende generalizar, sino que, a través de un enfoque cualitativo, identificar las representaciones y, a partir de los casos, describirlas, analizarlas y contrastarlas a partir de un análisis de discurso extraído de las entrevistas realizadas con los sujetos seleccionados para la muestra.

Los sujetos sociales seleccionados para este estudio fueron 18 ciudadanos. Esta distribución se hizo asi para tener tres generaciones: la de la posguerra (jóvenes), la de la guerra (adultos) y la que ha vivido la 
preguerra, la guerra y la posguerra (adultos mayores). Estos habitantes son personas comunes, que tienen por lo menos 15 años viviendo en el barrio o la colonia. Los adultos mayores debieron tener al menos 25 años viviendo en el lugar y los adolescentes y jóvenes, al menos 15 años viviendo en el barrio o la colonia. Fueron informantes claves, ya sea por el tipo de actividad que realizan en el espacio (comercial, religioso, trabajo), por vivir en calles o barrios inseguros o por haber padecido la inseguridad o padecerla $y / 0$ por haber tomado medidas ante la inseguridad como intentos por mudarse, contratar seguridad privada y otros. Fue importante establecer la diferencia entre hombres y mujeres porque no se tiene la misma percepción sobre la inseguridad a partir del género. No se consideró la estratificación económica para esta selección. Sino la clasificación por territorio y por edad. Toda la información se analizó discursivamente a partir de las siguientes categorías:

En el siguiente cuadro aparece una gráfica de las categorías y subcategorías de análisis del discurso.

\section{Dimensión sincrónica}

\begin{tabular}{|c|c|c|c|c|}
\hline $\begin{array}{l}\text { Espacio } \\
\text { (Territori/ciudad) } \\
\text { (Pasado/Presente) } \\
\text { Narrativas y Relatos }\end{array}$ & $\begin{array}{l}\text { Barrio/ } \\
\text { Colonia }\end{array}$ & Municipio & AMSS & País \\
\hline \multicolumn{5}{|l|}{ PreGuerra } \\
\hline Guerra & & $\begin{array}{l}\text { ACTOR SOCIAL } \\
\text { (matices culturales: } \\
\text { género, edad, } \\
\text { tiempo de vivir } \\
\text { allí, lugar de } \\
\text { vivienda, si profesa } \\
\text { alguna religión, } \\
\text { ocupación, } \\
\text { práctica) }\end{array}$ & & \\
\hline POSGUERRA & & & & \\
\hline
\end{tabular}

La primera como una unidad que constituye un eje horizontal y la segunda, un eje vertical. Así el tiem- po remite a episodios históricos, a narrativas y a experiencias de vida en momentos concretos que hacen 
posible darle un hilo conductor, una secuencia pasado-presente que han hecho entender el mundo de la vida de una manera particular y distinta a la de otros tiempos. La unidad tiempo tiene tres categorías: preguerra, guerra y posguerra. La se- gunda unidad responde al espacio la territorialidad, el contexto urbano, la ciudad. Esta tiene cuatro categorías: barrio, municipio, AMSS y país, que en algunos momentos no pueden separarse y en otros son espacios totalmente ajenos.

\section{El espacio: territorios de inseguridad/seguridad}

\section{A. El Barrio o colonia: liminalidad y fronteras simbólicas}

- I espacio donde habitamos no - es solamente el área demarcada en la que nos desarrollamos y vivimos, sino también el territorio que construimos física y simbólicamente. Tanto lo primero como lo segundo implica pensar el espacio como un lugar de relaciones que las personas establecemos, ya sea por oposición, por afinidad, por cercanía, por lejanía, por vecindad, por antipatía o simpatía, etc. En el caso de las personas entrevistadas, les pedí que hablaran de la seguridad en sus barrios o colonias, municipio, el Área Metropolitana y finalmente el país, precisamente, para poder ubicar la inseguridad en ciertos espacios, desde lo particular a lo general. Estas dos categorías: el barrio y el municipio, según algunos informantes aparecen separadas y para otros, unidas. Es igual hablar del barrio y del municipio o es absolutamente diferente.

Al preguntarles a los sujetos sociales por su barrio o colonia, a pesar de haber seleccionado, ba- rrios y colonias consideradas inseguras dentro de sus municipios -en Soyapango Los Santos I y II, en San Salvador, los barrios San Esteban y Lourdes y en Antiguo Cuscatlán la comunidad la Lupita y habitantes del centro-, de los 18 habitantes entrevistados al menos 11 reconocieron sus colonias y sus barrios como seguros. Pero no necesariamente porque lo fueran, sino porque les resulta tan cotidiana la convivencia con el peligro, con la delincuencia, que les resulta menos visible y menos padecible, que el peligro que se encuentra más allá de las fronteras de su barrio o colonia. De esos 11, seis eran de Antiguo Cuscatlán, tres de Soyapango y dos de San Salvador. Todos afirmaron que aunque sus barrios y colonias pueden considerarse inseguros, la inseguridad en realidad es lo que circunda a sus barrios. Siempre la inseguridad es más intensa en el afuera. En parte porque están tan habituados a convivir con la inseguridad que la asumen como normal, cotidiana y, por ello, menos peligrosa. Sin embargo hubo diferencias clave por munici- 
pio, edad y género. Los sujetos que mejor evaluaron a su barrio y municipio y que de hecho igualaron ambas categorías en el discurso fueron los de Antiguo Cuscatlán. Para ellos, la inseguridad existe, pero fuera, en las fronteras del municipio:

"Me agrada porque es tranquilo. En cuestión de comercio es bueno y va progresando todo lo que es comercio" (adulta)

"Esta parte es un lugar bien seguro $y$ lleno de tranquilidad a comparación con otros municipios. Acá es bastante tranquilo" (adulto)

"Todo me agrada porque la gente es llevadera con uno y las señoras son amables y tranquilas" (adulta mayor)

"Si, me gusta. Todo. El ambiente. No hay pandillas, ni nada por el estilo así. Es bien tranquilo y todo está cerca" (joven mujer)

"... Tengo muchas cosas cerca como el parque, la cancha, los ciber, la biblioteca y es tranquilo.Y lo que me menos me agrada... no sé. Sería nada porque todo me agrada de acá. Me gusta vivir acá" (joven bombre)

Esa porción territorial les resulta familiar, idónea, segura, agradable. La representación de la inseguridad, por lo tanto, no está dentro de su coIonia o municipio. La metáfora del dentro y el fuera en Antiguo sí se extiende a las fronteras del municipio, según los informantes entrevistados. Existe en los seis habitantes entrevistados un sentimiento de apego hacia su barrio y hacia su municipio: el paraíso en una ciudad caótica.
Mientras que para los habitantes de los barrios San Esteban y Lourdes de San Salvador, las fronteras son más restrictivas. La frontera de la inseguridad puede ser la casa, y fuera de la casa la calle donde habitan, los vecinos y cualquier extraño. Pero en este caso los límites si se diferencian de una generación a otra ya que para los adultos mayores el peligro es real, pero, por su edad, consideran que se hace relativo, ya que viven en tal reclusión y padecen de tal manera la exclusión, que la inseguridad parece no tocarlos $y$, de alguna manera, también los excluye. Ellos ya están grandes y ya vivieron, pero además ya no tienen necesidad de salir, por lo tanto optan por la reclusión por el retiro en sus casas:

"No me agrada, pero me conviene y me resigno. Me conviene, porque yo dependo del negocio, primero que en la misma casa tengo el negocio, área de campo, área recreativa, las 3 cosas en el lugar (...) No tengo necesidad de salir. Así que acá vivo yo en mi mundo... a parte claro de lo que está afuera" (adulto mayor)

"...Pues como no tengo otro lugar (Rie mucho). Como no tengo pues... y como aqui se criaron mis hijos y por la ubicación (...)o que es por mí... no pasa nada (...)"La de San Esteban dicen que es una zona peligrosa. Pero, como le digo... puede ser, pero depende (...) y yo como por lo menos con todo eso yo solo paso encerrada... y es que por eso que a veces no me doy cuenta." (Adulta mayor)

Para esta generación, el encierro de los toques de queda de la 
guerra se repite. Solo que esta vez es un toque de queda que se da de manera simbólica, "voluntaria" en el sentido de que pueden salir si lo desean, pero no deben salir porque se arriesgan. Estos dos informantes coincidieron en el encierro. La frontera es la casa, ni siquiera es el barrio. Las calles en las que viven son zonas rojas de tráfico de drogas. Ambos están consientes del peligro, pero existe resignación e indefensión acerca de la situación del barrio

En el caso de la generación adulta, la representación del barrio cambia. Sus fronteras de distienden en función de la necesidad que tienen de salir de sus casas, de transitar por el barrio y de aprender a convivir y subsistir con el peligro:

"Aunque muchos dicen que es peligroso y todo, pero para mí no es peligroso. No es peligroso porque realmente pienso de que el peligro puede suceder cuando nosotros andamos haciendo algo malo, pero si yo soy una persona sana y bien portada, pues no debo de temer porque no bay problema por qué afligirse por qué preocuparse porque el que nada debe nada teme" (Adulta).

"Pues yo como aquí crecí y como hemos vivido aqui cerca siempre. $Y$ antes era tranquilo y todo bien accesible. $Y$ yo pues porque ya la costumbre de vivir aqui, todo nos queda céntrico (...)Lo que me agrada tanto... realmente aquí este... no es una zona segura pues. No es seguro. $Y$ cuando no es una zona segura no le da a uno la confianza como para... para estar tranquilo vea. Pero... (Pau- sa) se puede vivir. Porque uno conoce a las... personas vea" (Adulto).

Esta generación está consciente del peligro que I rodea. Sin embargo, la representación del barrio inseguro es relativa, en cierta parte, debido al comportamiento que adopten con el peligro. Es decir, a evitar los problemas. Esa norma de convivencia informal, implícita a las relaciones cotidianas en el barrio, hacen que su vida sea menos arriesgada e incierta. Conocer a las personas que tienen o que representan el peligro en el barrio les permite establecer límites en sus hábitos $y$ en sus acciones. El barrio por lo tanto obtiene la representación del riesgo, de la precariedad, del tráfico de drogas que sin quererlo, les resulta cotidiano. Pesa la costumbre y aunque ellos mismos afirman que no se puede estar totalmente tranquilo, se puede vivir. Esto durante la guerra no era así.

En el caso de los dos adolescentes entrevistados, la inseguridad en el barrio tiene su propio rostro. Para ellos existe dos tipos de peligro en el barrio: los policías y los otros jóvenes. Afirman:

"Bueno, primero las drogas que aquí hay por todos lados, ventas. Luego... el alcobol. Las maras también y los disturbios a veces se oye que matan a alguien (...) aqui bay demasiado vandalismo, en todas partes (...)lo que a mí me causa un poco de temor son los mareros que andan fumando. Que andan con pistola, con camisa como gabanes. Esos son los que normalmente me dan miedo. Pero a ve- 
ces veo que andan normales, pero que se hacen señas con otros jóvenes y entonces son peligrosos" (Joven mujer)

"Yo tengo unos amigos que les han disparado bastantes veces en las piernas o en esto del pecho. Por eso es que no me presento mucho con ellos porque si me miran con ellos también puedo irme en la colada (...)A mí una vez me agarró un policia porque me dijo de que si andaba drogado y me pegó un macanazo, a veces sí es cierto verdad, a los jóvenes les traen gana, pero a un adulto no, ganas de encerrarlo, más en el caso de las pandillas boy hasta niños bay en las pandillas" (Joven hombre). Para ellos la frontera son ellos mismos. Bauman (2001) cita a Toqueville cuando este afirma que el individuo es el peor enemigo del ciudadano, como dijo el mismo autor. El individuo tiende a desentenderse, a ser escéptico o precavido respecto del bien común, de la buena sociedad o de la sociedad justa. En suma, el otro lado de la individualización parece ser la corrosión y lenta desintegración de la ciudadanía. En ese sentido, la representación del joven delincuente, el que es igual a ellos pero que puede ser su agresor, el amigo que puede comprometer, el que anda en malos pasos y que los puede arrastrar hacia el peligro. Sin embargo, ellos se sienten víctimas y victimarios, dos caras de la misma moneda. Son las víctimas, los perseguidos, los señalados, pero al mismo tiempo son los perseguidores. Ven por ello en los policías una representación llena de contradicciones. Por una parte es la autori- dad que los reprime y persigue, el verdugo, pero por otra es la autoridad que a veces tiene razón, que a veces sí es cierto. El barrio, por lo tanto, es un territorio de la inseguridad, pero la casa, su casa, es el territorio seguro, bajo el abrigo de sus familias. Sin embargo, para ellos existe otra percepción de dentro y fuera. Los de adentro, sus amigos son menos peligrosos porque los conocen, aunque representen un riesgo en presencia de un policía. Mientras que el joven de afuera se transforma en una amenaza contundente. Hay que entender además que no es lo mismo, territorialmente hablando, ser un joven en el barrio Lourdes que un joven de Los Santos I o uno el centro de Antiguo Cuscatlán o "La Lupita". El territorio marca un estigma de clase que pesa sobre los hombros del joven.

En el caso de los habitantes de Soyapango, la representación del barrio se repite en el caso de los adultos mayores. En el caso de los dos adultos de Soyapango de la colonia Los Santos II, de nuevo se enfatiza el estatuto de dentro y fuera. Para ellos sus pasajes amurallados y cercados, en donde tienen un vigilante que controla los ingresos, es tranquilo. De nuevo la política del encierro. Ya no en la casa, en el pasaje, como alternativa para garantizar la seguridad, pero Salir es el problema. Afuera representa peligro, incertidumbre. Los vecinos peligrosos y sobre los que no hay acuerdos que otorguen a estos individuos, garantías de seguridad. En 
el caso de los jóvenes de nuevo se repitió la tendencia de San Salvador, dado que para ellos el peligro está incluso dentro, entre ellos, con ellos y por ellos: los jóvenes. Y de nuevo el policía toma la representación del verdugo, el aprovechado, el perseguidor:

"Dónde yo vivo si es (peligroso, se refiere a Los Santos I), creo que es la zona más peligrosa que bay aquí, pues digamos ahi, ha habido bastantes asesinatos (...)Si llevo un compañero, personalmente tiene que ir conmigo, yo lo tengo que llevar porque si va él sólo le pueden hacer algo, porque como es desconocido (...)Si, en mi casa, pues no allí adentro, en la colonia pues, bay muchos peligros" (joven bombre)

"Aqui es tranquilo, la mayoría de veces. Es bastante tranquilo(,„,) $A$ veces hay que tener cuidado con los policías porque solo lo ven a uno y ya lo andan queriendo fregar" (joven bombre)

"En mi colonia, allí han matado a varias personas. La mayoría son bolos (borrachos), que ban matado allí los mareros. $Y$ a veces gente de ellos mismos. Sí he visto algunas veces" (joven, mujer)

Existe en ellos, una conciencia de que el peligro está incluso adentro, pero han aprendido a convivir con él. La frontera es relativa, la liminalidad es difusa, engañosa y movediza. Tienen momentos de tranquilidad, pero no saben cuánto van a durar. Para ellos la colonia es un territorio inestable: ocurren asesinatos y el peligro es una constante, sin embargo, la misma cotidia- nidad to hace relativo, conocido y hasta normal.

\section{B. El Área Metropolitana de San Salvador}

Cuando las fronteras se extienden, crece la sensación de inseguridad en la ciudad $y$, por lo tanto, la percepción de una ciudad insegura es mayor y más frecuente. A pesar de que todos los informantes de Soyapango, como los del centro de San Salvador, están conscientes del peligro dentro de sus barrios, hay una representación del "otro" dentro el barrio que lo hace menos otro, menos ajeno, que a ese otro que se encuentra afuera de las fronteras del barrio $y / o$ del municipio. Al hablar de la ciudad, entendiéndola en el sentido amplio, el del Área Metropolitana, los entrevistados iban incrementando sus adjetivos referidos al peligro, la inseguridad y la delincuencia. La imagen de la ciudad representada se vincula hacia la ciudad caos, la ciudad en donde cada vez más hay menos espacios abiertos que sean seguros. Tal parece que el estado de sitio vivido y padecido durante la guerra hoy se repite con la diferencia de que los límites existen aunque se tenga la libertad de salir, el paclecimiento de una sociedad sitiada (Bauman, 2002). De los 14 municipios del Área Metropolitana de San Salvador, en donde se concentra la tercera parte de la población total, también se hace necesario hablar de segregación y exclusión, ya que los municipios del norte siguen siendo 
periurbanos y todavía tienen características territoriales rurales y falta de acceso a servicios básicos como en el caso de Aguilares, Nejapa, Guazapa y Tonacatepeque. $Y$ otros que se acercan más hacia el centro, aunque gozan de más servicios, se han establecido como espacios para maquilas, fábricas y viviendas populares como en el caso de Apopa, Soyapango, Ciudad Delgado e llopango. Mientras que en San Salvador (la capital), la segregación es más dramática, ya que hay zonas con niveles superiores de calidad de vida, con un nivel promedio hasta abajo del límite pobreza en asentamientos ilegales y zonas marginales como la Tutunichapa. Sin embargo, aunque existen zonas rojas en todos los municipios, los contrastes en San Salvador y Antiguo Cuscatlán son más dramáticos, ya que zonas residenciales como la colonia Escalón, en San Salvador, y Santa Elena, en Antiguo Cuscatlán, colindan con zonas marginales, que "afean" el paisaje y que se están tratando de reubicar. En el caso de los entrevistados pudieron observarse tres tipos de situaciones ante la pregunta de los municipios más peligrosos y menos peligrosos del AMSS. Por una parte, una tendencia a la autoexclusión que se traduce en no salir del municipio a menos que sea necesario, el desconocimiento de los otros municipios a pesar de su cercanía con ellos y la estigmatización de municipios a pesar de no frecuentarlos. Es decir, se tiene una representación de ciertos muni- cipios que no conocen, a partir de la información que reciben de los medios de comunicación y de otras personas. Ese es el caso del Centro Histórico de San Salvador y Soyapango, Mejicanos, Ciudad Delgado y Apopa, entre otros.

Soyapango aparece en el discurso de los entrevistados en Antiguo Cuscatlán como el municipio más peligroso del AMSS. Los informantes lo asocian a las maras, la delincuencia y el crimen organizado. Soyapango representa el espacio heterotópico, ese espacio amenazante, donde se construye la otredad, según Reguillo, es aquel espacio oscuro, amenazante, lo peligroso, terrorífico, el color sepia de la película Tráfico. Sin embargo, las experiencias de peligro que han vivido o presenciado los informantes se han dado en autobuses y no en el territorio. Habría que hablar del autobús y de las líneas que circulan por estas zonas, como espacios, como lugares para la delincuencia, como lugares de riesgo. Para este caso además, las representaciones actúan, como afirma Tania Rodríguez (2003:12), como antecedentes de conductas ancladas a un sistema de creencias ampliamente compartidas entre los miembros de un grupo, por esa razón adoptan ciertas conductas activas o pasivas como rezar, bajarse del autobús, no visitar esos lugares y si es inevitable ir, absolutamente nada. La percepción de todos los entrevistados acerca de cuál es el municipio más peligroso del AMSS, en general, fue la de So- 
yapango. Lo describen como violento, inseguro, lo asocian a las maras y a los homicidios. Sin embargo, y aunque es cierto que este es uno de los municipios más violentos del AMSS, según el Informe Anual de Medicina Legal para el 2006, San Salvador tiene una frecuencia de homicidios de 522 correspondiente a un $13.3 \%$ del 100 y Soyapango tiene una frecuencia de 248 correspondiente a una frecuencia de 6.3 $\%$ sobre 100 y Antiguo Cuscatlán posee una frecuencia de 13 correspondiente a un $0.3 \%$. Sin embargo, la representación sobre el municipio más inseguro que construyen los entrevistados es la de Soyapango como el espacio heterotópico en el que se constituye la otredad, más que en San Salvador, aunque hablar del Centro de San Salvador, específicamente, se aproxime al estigma de Soyapango como espacio de peligro. La otredad según Octavio Paz (1970:103), "es una proyección de la unidad: la sombra con que peleamos en nuestras pesadillas; y a la inversa, la unidad es un momento de la otredad: ese momento en que nos sabemos un cuerpo sin sombra -0 una sombra sin cuerpo-". Esa otredad que por oposición a lo que no se es, se hace necesaria para mantener el equilibrio social, esa sombra de la que habla Paz, que finalmente se consolida en el cadáver oculto en el desván de una sociedad, cuyo pasado e historia de exclusión se sigue reflejando en el presente.

En el caso de los informantes del Centro de San Salvador la experiencia es distinta. Ellos, como ya he afir- mado antes, conviven con el peligro dentro de sus barrios. A ellos, aunque su territorio es peligroso, siempre les parece que el peligro es mayor afuera. Pero hay afuera (heterotópico) y afuera (utópico) debido a que para los informantes del Centro de San Salvador, específicamente para los jóvenes, el peligro está en las calles del centro, en la escuela y, simbólicamente representado y enmarcado en Soyapango. Mientras que para los adultos, el peligro que ciertamente también ubican con Soyapango, se comparte con Ciudad Delgado, Cuscatancingo y Mejicanos. Los adultos mayores, por su parte, generalizan ambos. El peligro está en todas partes. Sin embargo, ellos ya no salen, han optado por recluirse en sus casas para evitar el peligro, en su espacio, su territorio o espacio tópico, es decir, ese espacio al que pertenecemos y que nos pertenece, que nos es cotidiano, conocido y en el que nos sentimos seguros: la casa o, como afirma Reguillo (2006: 8), es el espacio donde yo me siento segura, donde estoy bien, el espacio que conozco y en el que me puedo mover. El espacio heterotópico (externo, peligroso) sigue ubicándose en Soyapango. Mientras que al preguntarles por los lugares del AMSS que les parecen más seguros, los espacios deseados (utópicos) para vivir respondieron que Antiguo Cuscatlán, Santa Tecla y la colonia Cima, así como parte de la colonia Escalón.

En el caso de los jóvenes, no solo de San Salvador, sino de $\underline{\text { So- }}$ yapango, ocurre que la segrega- 
ción simbólica, a la que han sido forzados, los hace desconocer la ciudad. De hecho, en las entrevistas, los jóvenes de San Salvador y de Soyapango tuvieron dificultades para ubicar otros municipios ajenos al suyo así como nombres de colonias de afuera de sus límites municipales. En algunos casos afirmaron: "He oído hablar de Santa Tecla, pero nunca he ido" (Mujer joven, Soyapango). Por lo tanto, ni siquiera aspiran a una mejoría en su situación, ya que afirman no es posible irse a otro lado. En este caso la segregación atiende a dos sentidos de los tres planteados por Dansereau (1993 citado en Séguin comp. 2006: 15). Primero en la referencia a la constitución de zonas relativamente homogéneas, pero que al mismo tiempo resultan ser diferentes de otras y segundo, el de la segregación vista como un proceso en el cual los actores desarrollan estrategias para apartar a los miembros de otras categorías sociales. Es precisamente la lectura entre líneas de los jóvenes de San Salvador y Soyapango:

"Me gustaría salir de aquí, vivir en otro lugar más bonito, vaya, más agradable y sin mareros(...) Me gustaría vivir...bueno no sé... en una zona donde no hubiera peligro de pandillas. Ni peligros de que vaya a llegar una persona a matar o hacer algo así. Algo tranquilo. Una zona en la que no hubiera problema" (Mujer joven de San Salvador)

"Acá en Soyapango. Sí. Acá me gusta. Ya estoy acostumbrada" no sé, ahí no le podría decir muy bien verdad. Si he visto muchas maras ahí en esta zona, pero en las demás no" (Hombre joven, Soyapango)

Este sentido de autoexclusión de los jóvenes se manifiesta en algunas de las citas anteriores. Pero también resulta interesante ver cómo ellos mismos se perciben como una población vulnerable al peligro, cercana al peligro porque los delincuentes, en su mayoría, afirman, son jóvenes. Hay acciones de construcción de infraestructura que enfatizan esa fragmentación y es la construcción de centros comerciales y colonias, residenciales de vivienda popular en la zona de Soyapango. De hecho, cuando se les pregunta a los jóvenes de Soyapango sobre su espacio ideal, afirman que les gustaría vivir en Bosques de la Paz, una zona residencial con seguridad privada en Soyapango: "Bosques de la Paz es de Soyapango, ahí ese lugar... creo que es el mejor porque es privado, entonces sólo esa zona, ahí las demás no" (Hombre joven, Soyapango).

\section{El país de los recelos}

En la medida que las dimensiones espaciales crecen, crecen los miedos y la representación del país inseguro. Todos, absolutamente todos los entrevistados, afirmaron que uno de los problemas más serios del país es la inseguridad junto a problemas como la pobreza y el desempleo. De hecho, en algunos casos plantean a la inseguridad como consecuencia de estos dos problemas. Hablan de la relación causa- 
efecto que se traduce también a la relación histórica guerra-posguerra.

Los habitantes de Antiguo Cuscatlán a pesar de tener un entorno cotidiano seguro dentro de su municipio, al preguntárseles sobre los problemas del país mencionaron la inseguridad: "Yo a un joven como vos, a mis hijos, yo les digo que si pueden irse que lo hagan. Porque acá se queda el que ya no tiene opción o bueno los que queremos luchar. Yo le apuesto a este país, pero a mis hijos yo si les digo que se vayan" (Adulto mayor, Antiguo Cuscatlán)

Todos los informantes admitieron que el país tiene problemas graves de inseguridad. Sin embargo, esa representación genera otras representaciones que sirven para justificar y/o explicar la situación que vive el país tales como que la situación actual de inseguridad del país resulta lógica debiclo a la guerra que vivimos, que quedaron acostumbrados a la violencia de la guerra, acuerdos incumplidos, mucha gente con armas que no se entregaron o que simplemente esto se vive en todas partes. Sin embargo, generacionalmente, los adultos mayores, tanto hombres como mujeres, optaron por la reclusión y la autoexclusión. Ellos "Ya vivieron" pero los jóvenes no. Dentro de la representación del país inseguro cuyo problema más grande es el económico, según los adultos de los tres municipios, el país es responsabilidad de todos, no solo del presidente o el gobierno. En el caso de San Salvador, la represen- tación del país violento recupera, de los adultos mayores de Antiguo, la aseveración del país con problemas sociales y económicos serios y en el caso de la mujer, de nuevo, surge la proyección de la exclusión social por la edad y el género:

"Así como está uno ya y uno ya vivió" (Adulta mayor, Antiguo Cuscatlán)

"Bendito Dios nunca me ha sucedido nada, ni a mi familia tampoco. A nadie. A ninguno porque mi hijo trabaja en el estadio, mi hija es enfermera y bendito sea Dios que él me los cuida. Me cuida a todos mis hijos, mis nietos porque nunca les ha pasado nada" (Adulta mayor, San Salvador)

Surge la extrapolación de los temores y preocupaciones hacia los hijos. En el caso de los hombres adultos mayores, el rol tiende a ser más externalista, menos emotivo, no tanto hacia la preocupación por los hijos, sino más socialmente ampliado, con mayor énfasis en la política.

El caso de los adultos de San Salvador es indispensable destacar el desencanto en la posguerra. La representación del país de la desilusión. Esta es una generación más desencantada. Pero hay que recordar que está fue la generación de la guerra. La representación es la de un país en crisis, en caos, en desorden. La tierra de nadie que no acoge y donde la solidaridad no cabe, porque ayudar los lleva a la muerte. Para los jóvenes, su princi- 
pal preocupación son ellos mismos. El país está mal, y ellos son víctimas y presas de una sociedad violenta. Existe un dato muy relevante con respecto al género y es que el espacio resulta más excluyente para mujeres que para hombres y eso las obliga a tener fronteras más estrechas y horarios más restrictivos para salir. Pero también eso realza su rol socialmente construido de la mujer que cuida "care", la que se preocupa por la familia y vela por el bienestar emocional y afectivo familiar.

En el caso de San Salvador, la representación del país violento recupera, de los adultos mayores de Antiguo, en el caso del hombre, el país con problemas sociales y económicos serios y en el caso de la mujer, de nuevo la proyección de la exclusión social por la edad y el género: así como está uno ya y uno ya vivió, surge la extrapolación de los temores y preocupaciones hacia los hijos. En el caso de los hombres, adultos mayores, el rol tiende a ser más externalista, menos emotivo, más socialmente ampliado.

En general de esta muestra cualitativa, los y las sujetas sociales tienen la representación de un país corrupto, que no puede cambiar en sus bases. Hay un discurso que revela la indefensión de los sujetos sociales, ante el problema de la inseguridad como consecuencia de las secuelas de la guerra. Hay un doble discurso de un país en crisis que sin embargo ha ganado mucho por no estar en guerra.

\section{Temporalidad: Posguerra, guerra y preguerra}

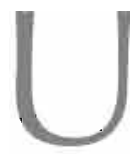

no de los hallazgos más relevantes de las representaciones de la inseguridad en el posconflicto es que la inseguridad es representada como un fenómeno omnipresente, que no solo se da en El Salvador, sino en el mundo entero. Vivimos, como afirma Giddens (1990: 22), "en un mundo espantoso y peligroso". Pero a pesar de esa conciencia universal acerca de la inseguridad y no solo desde su acepción con la violencia y la delincuencia, sino en el amplio sentido de dicho concepto, los informantes también ubican el fenó- meno de la delincuencia desde una evolución histórica particular para el caso de El Salvador: la guerra y sus herencias. De manera que aparece la representación social de la inseguridad heredada que, de alguna manera, sirve para justificar el estado de las cosas. Un estado que ellos mismos calificaron como agobiante, anárquico, alarmante, peligroso, tremendo, etc. Pero que desde su representación de la crisis que generó el fin de la guerra, no solo es lógico, sino esperable. Toda guerra deja estragos, cambios problemas sociales y reajustes. 
Para los entrevistados, en particular para los adultos y los adultos mayores, la guerra no solo representó la destrucción y el enfrentamiento entre dos fuerzas que les eran ajenas, la guerra de otros, sino también representó el encierro y el estar en el momento y el lugar equivocado, ya que esa guerra no era contra ellos. El peligro era, en términos fortuitos, una bala perdida, o encontrarse en un fuego cruzado. Sin embargo, no hay que olvidar que los entrevistados son sujetos urbanos y que la guerra fue fundamentalmente rural. De los 18 sujetos sociales entrevistados, solo 12 vivieron la guerra, por razones generacionales, pero de esos 12 solo una vivió la guerra en el campo. Los demás la observaron, desde el telón de fondo de la ciudad. No obstante, no por no haberla vivido y padecido más que episódicamente, como describieron - a través de la ofensiva final en la ciudad en noviembre de 1989- esto implica que no exista en ellos una memoria del conflicto, que no solo los ha marcado, sino también los ha hecho adoptar ciertas actitudes y posturas frente a las nuevas problemáticas sociales. Flores (2000: 115 en Jodelet y Tapia,coord.) afirma que "el relato como ficción es una forma de ordenar y estructurar los recuerdos que permitían un acercamiento a la percepción que la muestra tiene de sí misma". A partir de esta cita hay que entender que la representación se construye para representar una realidad vivida, experimentada, percibida, o imaginada pero que constituye al sujeto social como tal. Sin embargo, coincidieron en que el tipo de inseguridad que se vivió fue distinta y al momento de preguntárseles si era más segura o insegura la guerra con respecto a la posguerra, respondieron, en el caso de los adultos que fue la generación de la guerra, de manera dispar de un municipio a otro. Para los adultos y adultas de Antiguo Cuscatlán la posguerra es mejor, a pesar de las problemáticas de inseguridad nacional y las desigualdades económicas, mientras que para los adultos de San Salvador, la guerra era insegura por una bala perdida, o por estar en el momento $y$ en el lugar equivocado, pero hoy la guerra es social y es peor:

"El barrio hace... 20 años atrás, sí era un barrio mucho más tranquilo. Se nota la diferencia entre décadas verdad. 20 años atrás uno podía caminar por el... por el... por aquí a medianoche y era tranquilo, vea. EI comercio era distinto" (Adulto, San Salvador)

"Eh... siento que... era mucho más seguro que ahora porque... mmm, porque... en ese tiempo... o sea, se sabía que... había una guerra civil. Se sabía que las... (Pausa) los dos bandos, tanto guerrilla como el ejército, ellos se enfrascaban en su... en su guerra" (Adulto, San Salvador)

"...Cuando vemos que andan las maras, vemos, pues, que está peor. Peor. $Y$ si ves en las noticias que están dando, que están man- 
dando... parece que hasta la fecha llevamos 7 mil deportados o 16 mil, una cosa así. Y vos crees, es que la mayoría de esos son mareros, pues. Porque allá han estado en maras y entonces eso es una cosa grave para el país." (Adulta, Soyapango).

Las citas anteriores destacan que los ciudadanos identifican el tema de las maras como una herencia de la guerra. Las deportaciones que iniciaron con la finalización de la guerra y los sectores que tenían como ocupación la guerra y que tuvieron que cambiar su estilo de vida fueron, según estos ciudadanos, un detonante en la situación actual. La inseguridad en la posguerra representa la indefensión. El encierro obligado de la guerra por los toques de queda y por los enfrentamientos esporádicos en la ciudad no es el encierro de hoy. La reclusión a la que los sujetos se han visto forzados es simbólica, es cotidiana y es real. Hoy el encierro no es a causa de un ataque fortuito, sino por un ataque incontrolable en una guerra que es de todos contra todos. La guerra sin guerra. Los adultos, al igual que en el discurso de los adultos mayores, destacan que hay situaciones que no les satisfacen en el ahora, como la presencia de otras personas que han migrado al barrio (los otros, que modifican y desarmonizan el nosotros), y la inseguridad:

"Y antes era tranquilo y todo bien accesible" (Adulto, San Salvador)

"Realmente aquí... no es una zona segura (...) Pero se puede vivir" (Adulto, San Salvador)
"Porque uno conoce a las... personas (...)Hay cositas que a veces no le agradan a uno porque uno las ve(...)Y siento que aunque mucha gente dice: 'Ese lugar es terrible, ese lugar nadie puede pasar ahí, para mí no lo siento así porque hasta el momento, en el tiempo que tengo de vivir acá, nunca nadie ha tratado de hacerme daño" (Adulta, San Salvador)

En los fragmentos anteriores, los entrevistados hacen una diferencia entre el peligro para alguien que no es del barrio y para ellos. En este caso para el sí mismo, sea en primera persona o en impersonal, el peligro es relativo. Porque en su caso, el peligro les resulta cotidiano, familiar, "normal" incluso. Ellos conocen las rutinas, los rituales de convivencia del barrio como afirma Mauro Woolf (2000:51):

“Siempre que el sujeto está en presencia de otros debe mantener un orden ceremonial por medio de rituales interpersonales. Está obligado a tratar de actuar de forma que las consecuencias expresivas de todos los acontecimientos que se verifiquen en aquel lugar sean compatibles con el resultado que él y los demás presentes poseen..."

Estos rituales que son esperados y necesarios en toda relación entre grupos, en el Barrio San Esteban de San Salvador se generan en función de la supervivencia, de la seguridad, de la vida misma. El mí y el uno habla desde la experiencia, desde la tolerancia y la omisión. Por 
eso aunque el peligro existe, ellos pueden vivir en el barrio. La representación del barrio en la posguerra es la de la tolerancia, pero la de la tolerancia vinculada a la pasividad, la resignación, la omisión del peligro que existe y es real, en un peligro que los excluye en la medida que conocen a los nuevos otros. El barrio en la posguerra representa la juventud que delinque, las drogas, la delincuencia que los circunda y los invade y que, sin embargo, por acuerdos tácitos que nunca nadie ha garantizado, a ellos, no los toca.

Dentro de las citas recapituladas de los informantes de este grupo de edad predomina una representación social cuya función, en buena parte, es primero saber y luego justificar. Así es posible que al mismo tiempo que afirman que el barrio no es seguro, porque hay "cositas" o "gente" que no les agrada, porque les generan incertidumbre, desconfianza o temor, también es cierto que "se puede vivir" y que esas "cositas" o "gente" a las que hacen referencia forma parte de su vida cotidiana y de su barrio, y, como tales, les resultan conocidos y les permiten, al mismo tiempo, conocer las reglas de convivencia que les evitan buscarse problemas o conflictos y que garantizan su seguridad. La ambivalencia en el discurso y en las prácticas es normal.

La posguerra tiene el rostro de las maras. La guerra tuvo el rostro de la guerrilla y los militares, pero hoy las pandillas como consecuen- cia de las deportaciones de jóvenes pandilleros y de la ausencia de los padres que migran han generado la representación del joven delincuente en una posguerra con una juventud agresiva, que se involucra en pandillas, drogas y el crimen:

"Entonces comenzaron a proliferar, los pequeños grupos de jóvenes y empezaron a llamarse maras, vea,... pandillas..."(Adulto, San Salvador)

A este grupo se le impone el estigma, el rótulo de "sujetos culpables", sin embargo la representación de la juventud perdida y sin valores se justifica como un fenómeno de la posguerra:

"Esto es parte de la posguerra, verdad, esta cosa de las maras. Eso se tenía que dar (...) es normal porque tenía que haber una transición entre la guerra y la paz" (Adulto, Antiguo Cuscatlán).

Recordemos, entonces, que las representaciones sociales emergen en contextos de crisis. Tajfel (citado por Mora, 2002) propone que las representaciones sociales requieren responder a tres necesidades: a) clasificar y comprender acontecimientos complejos y dolorosos; b) justificar acciones planeadas o cometidas contra otros grupos; y c) para diferenciar un grupo respecto de los demás existentes, en momentos en que pareciera desvanecerse esa distinción. En suma, causalidad, justificación y diferenciación social.

En el caso de los jóvenes, la representación de la posguerra es 
el único referente que tienen. Pero además, la categoría de tiempo, para este grupo de población, no solo es difusa, sino inexistente. No saben de la guerra, aunque han escuchado de ella, pero tampoco ven el futuro. Para ello es el aquí y el ahora, Para efectos de esta investigación, entrevisté jóvenes adolescentes de escuelas públicas de 15 ó 16 años, de barrios o colonias peligrosas dentro de sus municipios, y que están ubicadas en los alrededores de los centros de cada municipio o en el Centro. Hacerlos pensar sobre este tiempo, sobre su tiempo y reconstruir sus rasgos no les resultó fácil. Sin embargo, este es un tiempoque, de alguna manera, los persigue y los señala. Al explorar las respuestas que dieron en las entrevistas acerca del ahora, de su colonia, barrio, municipio, país en el hoy, no lograban describir su tiempo. No comprendían la noción del tiempo, de la temporalidad y de cómo puede esta haber cambiado sus vidas. Sus respuestas son estáticas, episódicas y no procesuales como en el caso de los adultos y los adultos mayores. Algunos de los comentarios que hicieron sobre su hoy se referían más al espacio que al tiempo en sí mismo.

A sus escasos 16 años, y siendo adolescentes, sus preocupaciones no solo son la escuela y la familia, sino su seguridad. La representación de la posguerra para ellos no es de posguerra, porque no la recuerdan, no la vivieron. Por lo tanto, su realidad, que siempre ha sido sin guerra, es y siempre ha sido conflictiva, desde que tienen capacidad de recordar. No existe, además, la noción de la historia, no solo hay falta de conocimiento sobre la historia reciente, sino falta de interés por conocerla.

Pero también, debido al deseo de no volver al pasado bélico, aparecenactitudes de conformismo y aislamiento autoaplicados. Ante la imposibilidad de cambiar las cosas, lo mejor que se puede hacer es no hacer nada. Surge la práctica social del no hacer, del no buscar problemas. La justificación es que inseguridad hay en todos lados y que no se puede cambiar y por eso hay que aprender a sobrevivir en un contexto adverso que no solo es familiar, es cotidiano, es rutinario. Giddens afirma que "lo rutinario es psicológicamente relajante; no obstante, en un sentido muy importante, también representa algo con lo que no todo el mundo puede sentirse relajado" (1990: 97) Podría decirse que los habitantes entrevistados de Soyapango y San Salvadorconviven de manera cotidiana con el peligro, la delincuencia y la violencia y mantienen una relación de tolerancia, complicidad que les brinda un mínimo de certezas a cambio del silencio. El silencio es una práctica social muy arraigada ante la inseguridad de la posguerra: Ver, oír y callar. "El reconocer la existencia del riesgo, o el conjunto de riesgos, es aceptar, no solo la posibilidad de que las cosas pueden ir mal, sino de que esa posibilidad no puede eli- 
minarse" (Giddens, 1990: 108). La inseguridad es una presencia que además no puede eliminarse y con la que hay que aprender a convivir. La inseguridad ha dejado de ser ajena y ha pasado a incorporarse en el sentido común y eso ha permitido la naturalización de la violencia. Se ha aprendido a vivir con la violencia. Aunque sería arriesgado afirmar que antes no lo hacían. Solo puede afirmarse que la violencia de la posguerra se representa la dualidad del riesgo asumido y negado a la vez. Es decir, se reconoce la presencia del peligro, pero se mantiene el discurso de "a mí no me va a pasar" como mecanismo de defensa.

En la posguerra existe además una nostalgia por lo bucólico. Es decir, por la apacibilidad del campo, principalmente, en el caso de los adultos mayores que añoran la época anterior a la guerra, es decir, la preguerra, que en contraste con la posguerra, es catalogada como una época de control, pero también de calma, de certezas, de autoridades. Existe, de hecho, una añoranza por el autoritarismo de las dictaduras militares, debiclo a que estas, a través de la fuerza, mantenían un control social del que actualmente se carece. Esta representación de la ausencia de fuerza y de control en la posguerra, sin embargo, se percibe con claridad, únicamente en el discurso de los adultos mayores y de dos de los adultos entrevistados, específicamente, el de Soyapango y el de San Salvador. De hecho, esta representación de la ausencia de control, también es visible a través de la representación del policía actual, como temeroso, con baja autoestima, débil, sin vocación, etc. $Y$ aunque en el caso de los adultos mayores de Soyapango y de la adulta mayor de San Salvador, los perciben como policías que, en su mayoría, tienen buenas intenciones, existe de parte de estos informantes, una justificación, casi una disculpa hacia ellos por no poder resolver el problema de la inseguridad, debido a la falta de recursos, a la gravedad del problema, los bajos salarios, etc.

Pero en torno a la policía como institución, en términos generales, los informantes reconocen una institución nueva, que no se parece a la Policía Nacional de la guerra y, sobre todo, que utiliza nuevos métodos para erradicar la delincuencia. Sin embargo, admiten que no se logra, de nuevo es por falta de recursos, fuerza y leyes que los amparen. De nuevo surge una disculpa, una justificación, una causa "lógica" que explica el uso de la fuerza de la policía hacia los delincuentes y los pandilleros. El Adulto mayor de Soyapango admite que: "No entendemos de otra manera". Incluso este personaje llega a admitir que "Han querido transformar nuestra sociedad y eso debe ser como gente civilizada. Pero como que nosotros estamos acostumbrados a que nos peguen así". Por lo tanto, se recurre frecuentemente a la imagen del salvadoreño conflictivo, incluso el incivilizado que solo entiende por la fuerza. En un artículo publicado 
en la revista ECA (Cruz, 1999:105) precisamente se habla de la importancia de estudiar las actitudes autoritarias de la población salvadoreña que aparecieron desde finales de los 90. En dicho artículo se afirma que diversas actitudes de los salvadoreños reclaman dureza y que también sienten menos aprecio por los derechos humanos, más preocupación por mantener el orden social y la intolerancia, pero, además, que están vinculadas a la población más desaventajada socialmente, la más pobre, la más marginada.

Pero las representaciones de la inseguridad tienen lugares, territorios en los que no solo es probable vivir un acontecimiento delictivo, sino que se transforma en más que una posibilidad, en casi una certeza para ciertos sujetos sociales. Todos, absolutamente todos los entrevistados, incluidos tres policías (uno de cada municipio) y un ex guerrillero, mencionaron a Soyapango como uno de los territorios de mayor riesgo en el AMSS en la actualidad. Sin embargo, como he presentado en páginas anteriores, según medicina legal (2006), San Salvador presenta mayores índices de homicidios que Soyapango con un porcentaje del $13.3 \%$ sobre el $6.3 \%$. Soyapango se asocia, se asume, como un territorio de maras. El territorio de la otredad más fácilmente identificable. Por supuesto, inseguridad hay en todos lados. Pero hay lugares marcados. Soyapango y el centro de San Salvador son algunos. Estos se consolidan en territorios de la exclusión. Tanto así, que en los barrios Lourdes y San Esteban del Centro de San Salvador se reconoce que no hay un puesto de policía establecido, sino un taIler, al que eventualmente acuden algunos agentes. En Soyapango hay un puesto de policía para el municipio y los entrevistados reconocen que sí hay patrullajes, pero que, en muchos casos, son intrascendentes y no resuelven nada. El punto es que aunque hay territorios localizados de la inseguridad y de la seguridad, cada vez es más difícil identificar o localizar a la inseguridad, debido a que la otredad se expande, se moviliza, se encubre. Emma León afirma que la otredad es "una condición problemática que pone a cualquier realidad ajena en un tipo de relación donde el YO o Nosotros tiene la posibilidad de cerrarse, proyectarse o abrirse. Puede dar lugar; por ejemplo, a un «analogón» o a un «alter-ego», que es expresión de una sospechosa igualdad, isomorfismo, o proyección, los cuales representarían el reducto último de esa ego- logía" (León, 2005: 123)

En ese sentido es que concluyo que las representaciones de la inseguridad están fuertemente ligadas no solo a los territorios, los lugares, los espacios de la exclusión- marginación, sino también a la presencia e incluso a la ausencia del otro. El otro es la frontera, parezca o no sospechoso. El problema es precisamente el encubrimiento, la relación del yo o del nosotros puede proyectarse en el otro como similar a mí, pero que no soy yo y no puede serlo 
aunque lo parezca. La categoría del nosotros tiende a cerrarse. Las prácticas de la segregación espacial se amplían al rechazo, al apartamiento de los individuos sociales que no forman parte de mi grupo aunque estén en mi territorio.

Ese es el caso de Soyapango en la colonia los Santos II, en donde los adultos entrevistados afirmaron que viven rodeados de sospechosos con los que no conviven más que a través del miedo y la desconfianza. Los otros, esos que están afuera del pasaje, afuera de las rejas y de la pluma de control son una amenaza latente. Las fronteras de lo seguro/inseguro que en el tiempo de la guerra respondían a identidades de grupos políticos y militares concretos, al campo y la ciudad, ahora son difusas, móviles y tienden a ampliarse. Alguien que puede parecer "normal", puede no serlo:

"No andan sucios, no vaya a creer (...)Hoy la gente se disfraza más que uno(...) No. Bien tipos andan" (Adultos mayores, Soyapango)

"Hoy no se puede confiar en nadie, porque a veces andan bien vestidos y resultan ser delincuentes" (Adulto San Salvador)

"Hoy los mareros ya no se tatúan, andan bien vestidos y todo" (joven Soyapango)

Por lo tanto, el estigma disfrazado (Goffman, 1964) de normalidad, hace que hoy la fronteras físicas sean más que eso: límites sociales que de demarcan las relaciones en- tre grupos y las diferencias de quién está dentro o fuera de dicho grupo. La cita de Peter Waldman explica tal situación: "A esto hay que añadirle que la definición de quien es 'amigo' o 'enemigo' es bastante borrosa y cambiante. Por lo visto, la gran cantidad de actores violentos colectivos así como la ausencia de un punto de referencia común, como sería la presencia de un Estado hegemónico, produce una compleja red de relaciones que slo permite adoptar decisiones situativas sobre quien debería ser considerado aliado y quien adversario. En otras palabras: se ha producido una discrepancia llamativa entre la fuerza constitutiva determinante de la dicotomía 'amigo-enemigo' con las consecuencias mortales que la acompañan, por un lado, la arbitrariedad con que personas o grupos son adjudicados a una categoría u otra."(Waldman, 2006: 181).

La reflexión de los hallazgos no queda aquí. Existen diferencias generacionales y de género en las representaciones sociales de la inseguridad. En el caso de los hombres, la inseguridad genera impotencia y miedo, rechazo al delincuente y al sospechoso y la necesidad de leyes más duras. En el caso de la mujer, la inseguridad refuerza el sentimiento de indefensión basado en la representación del sexo débil, pero, además, en el rol histórico de la mujer inmersa en el espacio privado y el rol de la mujer que cuida de su familia, emotiva, afectiva, protectora y sensible. Para las mujeres, la in- 
seguridad en la posguerra es mayor, porque, ahora el temor ya no es solo el de una bala perdida o que recluten a sus hijos, o que algo le pase a su familia, sino el de una violación, agresión, violencia, extorsión, etc., que aunque son temores históricos han adquirido más fuerza con el tema de las pandillas en la posguerra y su percepción machista y sexista acerca de la mujer como objeto.

Desde el punto de vista generacional, los grupos podrían dividirse así: la generación de la nostalgia por la ciudad pueblo y las demandas de medidas drásticas, que es la generación de los adultos mayores, cuyo discurso oscila entre la añoranza de una vida como en el pasado de la preguerra en la que se tenía una vida más intimista, cercana en armonía con la naturaleza, pero a la vez la demanda constante de orden, de leyes más duras, de acciones más fuertes. La generación del desencanto, que es la generación de los adultos. Esta es la generación de la guerra. La que en muchos casos le apostó a la guerra, le temió o la rechazó. Fue la generación joven durante la guerra y la que define hoy:

"Que la guerra solo dejó más guerra" (Adulta, San Salvador)

"Digamos que ha mejorado porque ya no hay guerra, pero nada por eso, porque la delincuencia y la pobreza está peor, de nada sirvió"(Adulta, Soyapang,)

"Yo no espero que ese problema se resuelva de aquí a unos diez años, no creo, cinco años mentira, eso es una gran mentira, no se va a poder resolver, pero mira lo que más me preocupa es que todavía no veo yo indicios de que estén trabajando las causas que están generando el problema(...)Yo pienso emigrar, fíjate, sí, estoy pensando así muy, muy, muy seriamente irme para Canadá" (Adulto, ex guerrillero, ex policía)

Para esta generación la guerra aún tiene saldos pendientes, expectativas irresueltas y deudas insaldables. Para ellos el país expulsa a sus ciudadanos. La política traiciona y la economía aniquila.

La última generación es la de los jóvenes, que no es posible poner en una sola categoría, a pesar de las resonancias en sus discursos. Esta generación es la generación de la indiferencia, la del aquí y el ahora "carpe diem", la de la rebeldía, la del peligroso y el inadaptado. Los jóvenes entrevistados tienen en común en su discurso tienen el estigma de incomprendido, pero, además, por la falta de referentes históricos y de conocimiento sobre la guerra, tienen poca conciencia de la inseguridad actual, como consecuencia, en parte, de la guerra de los 80. Ellos tienen una representación de la inseguridad en la ciudad, en el espacio, más que en la historia, en el tiempo. Pero se perciben a sí mismos como los actores potenciales de la inseguridad, pero también como las víctimas excluidas de una sociedad en la que se sienten ajenos. 
La objetivación de la representación del joven como agente de la inseguridad obedece a la existencia de las pandillas como consecuencia del fin de la guerra. El origen de las pandillas se vincula históricamente al momento en el que los jóvenes emigrados o de padres emigrados en la época de la guerra hacia Estados Unidos, al no encontrar un lugar en su país, ni en el país receptor, regresan empoderados, agrupados, resentidos a una sociedad que les debe un lugar en este mundo. Esa representación pesa, no solo en las generaciones adultas, sino en ellos mismos.

Pero hay que hablar también de las representaciones que dividen a los territorios y a los casos estudiados. Para los informantes de Soyapango, este municipio definitivamente es peligroso, pero por su experiencia de vida, un territorio de tolerancia y de supervivencia. Pero también, de gente trabajadora. En el caso de los habitantes entrevistados del centro de San Salvador, sus barrios y el municipio son inseguros. Pero específicamente el centro y sus barrios son riesgosos y han sido invadidos por unos nuevos "otros" que han llegado a hacer de este espacio un lugar de tráfico de drogas y pandillas. Para los informantes de Antiguo Cuscatlán, este es el espacio ideal en un territorio contaminado. Casi se concibe como una tierra prometida cercana al ideal de lo que debe ser una ciudad:próspera, segura, tranquila, agradable. Sin embargo, y aunque muchos reconocen que sus barrios no son del todo seguros, por las relaciones que establecen con el lugar y la cotidianidad del peligro y el reconocimiento del miedo como algo irremediable. Siempre, aunque sus barrios o colonias sean muy peligrosos y las estadísticas lo comprueben, siempre, el otro amenazante está afuera. Un afuera relativo y difuso, pero afuera. El miedo, como afirma Entel (2007: 30), "puede expresarse en el susto puntual ante un acontecimiento apabullante, una presencia no deseada y/o derivar en una gama de comportamientos que se reiteran $y$ tienden a que los sujetos experimenten actitudes de parálisis, aislamiento y hasta evitación de contactos con el mundo exterior, que es imaginado en su totalidad como amenaza". El miedo genera reacciones y acciones $\mathrm{O}$ inacciones muy concretas, tal y como lo afirma esta autora.

En torno a las medidas de seguridad que se toman, en torno a las prácticas de autodefensa y cuidado que se procuran los entrevistados, aparecen las prácticas sociales del amurallamiento, de la privatización de los espacios, del encierro, del silencio, de la seguridad privada, pero también y casi de manera generalizada entre todos los informantes la práctica de la fe como refugio, providencia y auxilio al afligido. Las representaciones sociales necesitan de reconocimiento social, de su materialización a partir de prácticas sociales concretas, de clasificación y de la reafirmación de éstas como hábitos en un tiempo y espacio par- 
ticular y socialmente articulado. La religión, en este caso, genera nuevas formas de participación social condicionada a la plegaria por un poco de seguridad. Aunque fue más frecuente identificar la práctica de la vida en la fe en los adultos y los adultos mayores, también los jóvenes de Soyapango manifestaron que lo único que pueden hacer es pedirle a Dios:

"Dios. Sólo Dios... Aquí no vale enfermo, no vale seguridad, sólo Dios... como le digo. Hay que orar por los tiempos." (Adulto mayor, San Salvador)

"Pues aquí solo la voluntad de Dios con uno (ríe) Él es el que nos da toda la seguridad y nos protege de todo."(Adulta Mayor, San Salvador)

“Para mí nadie, ningún autoridad ni nada...Solo el señor con nosotros." (Adulto mayor, Soyapango)

Ante la pregunta inicial si existe una influencia de las representaciones en las prácticas sociales urbana de la inseguridad, hay que decir que la afectación es mutua, constante y que existe una retroalimentación que confiere, tanto a unas como a otras, de legitimidad. Por ejemplo, la representación de la fe como el refugio potencializa la práctica de una creencia religiosa y una vida cristiana. Pero, también, la percep- ción de la omnipresencia de la inseguridad potencializa la práctica del encierro y del silencio. El duelo y la melancolía, como menciona Alicia Entel citando a Freud (2007: 31), como prácticas son importantes para entender los miedos en la posguerra. El duelo por la pérdida de la confianza y la muerte de las certezas mínimas y la melancolía por estados anteriores, por épocas, quizá menos adversas que las actuales. Finalmente, ante la pregunta que me formulaba en este texto al inicio sobre si estás representaciones sociales de los ciudadanos contribuyen o no a reforzar el concepto de ciudad ideal, la respuesta es no. Las prácticas solo les permiten sobrevivir de la manera menos riesgosa y más acorde a los tiempos de paz. Como afirma Entel (2007: 113), "la expansión de los miedos opaca y coarta otras actitudes que parecen emblemáticas en los tiempos de rebelión". Sin duda alguna, este no pretendió ser un trabajo cuantitativo y no permite generalizaciones; sin embargo, ofrece un material de reflexión sobre cómo el ciudadano salvadoreño de alguno de estos tres municipios se percibe, inmerso en una realidad social de un país que finalizó, hace 16 años, una guerra civil que cambió sus maneras de ver el mundo, la política, la supervivencia misma.

\section{Bibliografia}

Abric, Jean Claude (2004) Prácticas sociales y representaciones. $1^{\text {a }}$ reimpresión en español. México

D.F.: Ediciones Coyoacán 
Araya Umaña (2002) Las representaciones sociales: Ejes teóricos para su discusión. Cuaderno de Ciencias Sociales 127. Costa Rica: FLACSO

Baires, Sonia et al (2004). Violencia urbana y recuperación de espacios públicos. El caso del Área Metropolitana de San Salvador. San Salvador: UCA-PNUD. 28 pp.

(2003) Los barrios cerrados en el AMSS: Una nueva forma de segregación y fragmentación urbana. Paper presented at the LASA Conference March 27-29, 2003 Dallas, TX.

Bauman, Zygmunt (2006) En busca de la política. $2^{a}$ reimpresión. Buenos Aires: FCE

(2003) Comunidad: En busca de seguridad en un mundo hostil. Madrid: Siglo XXI

Berger y Luckmann (2005) La construcción social de la realidad. $1^{\mathrm{a}}$ ed. $19^{\mathrm{a}}$ reimpresión. Buenos Aires: Amorrotu

Berger, J. (1986) citado en Souza - Santos, B. (1991) Una cartografía simbólica de las representaciones sociales Prolegómenos a una concepción posmoderna del derecho. revista Nueva Sociedad No 116 Noviembre- Diciembre de 1991, ISSN: 02513552, <www.nuso.org>.

Berian, Josetxo (1990) Representaciones colectivas y proyecto de modernidad. Barcelona: Anthropos.
Córdova, Ricardo (1996) El Salvador: La nueva agenda de posguerra. Revista nueva sociedad No. 145. Septiembre - Octubre. Págs. 9-15.

Corte Suprema de Justicia. Instituto de Medicina Legal Dr. Roberto Masferrer. Unidad de estadísticas (CSJ) (2006) Anuario Estadístico "Defunciones por homicidio en El Salvador. Período enero- diciembre de 2006." San Salvador

Costa, Gino (1999) La Policía Nacional Civil de El Salvador. (1990- 1997) San Salvador: UCA editores

Cruz, M (1999) El autoritarismo en la posguerra. Publicado en La Revista Estudios CentroamericanosNo. 603 enero 1999 año LIV, Universidad Centroamericana "José Simeón Cañas", en San Salvador: UCA Editores.

De Alba, Martha (2006) Experiencia urbana e imágenes colectivas en la ciudad de México. ESTUDIOS DEMOGRÁFICOS Y URBANOS, vol. 21, núm. 3 (63), pp. $663-700$

De Sousa-Santos, Boaventura (1991) Una cartografía simbólica de las representaciones sociales Prolegómenos a una concepción posmoderna del derecho. Nueva Sociedad \#116. NoviembreDiciembre 19991, PP 18-38.

Ellacuria, Ignacio (1991) Veinte años de historia en El Salvador (1969 - 1989). Tomos I, II y III. San Salvador: UCA editores. 
Entel, A. (2007) La ciudad y los miedos. La pasión restauradora. Buenos Aires: Ediciones la Crujia.

Eriksson, J. y otros (2000) El Salvador Post- Conflict Reconstruction. Country Case Study Series. World Bank Operation Evaluation Department OED. Washington, D.C

Flores. F. (2000(a)) Psicología social y género. El sexo como objeto de representación social. México: Mc Graw Hill/ UNAM DGAPA

García, Sergio (2002) En torno a la seguridad pública. Desarrollo penal y evolución del delito, en Pedro José Peñaloza y Mario A. Carza Salinas (coords.), Los desafíos de la seguridad pública en México. México: Universidad IberoamericanaUNAM-PGR

Giddens, A. (1990) Consecuencias de la modernidad. Madrid: Alianza Editorial

Giménez, G. (2003) Las diferentes formas de discriminación desde la perspectiva de la lucha por el reconocimiento social. San Andrés, Totoltepec, marzo de 2003. Archivo electrónico consultado en Cultura y representaciones sociales. Un espacio para el diálogo transdisciplinario. http://www.culturayrs.org.mx/

Goffman, E. (1963) Estigma. La Identidad deteriorada. Buenos Aires: Amorrortu.
Habermas, J. (1989 Identidades nacionales y postnacionales, traducción de Manuel Jiménez Redondo, Tecnos, Madrid: pág. 121.

Hall, S. (1997). Cultural representation and signifying practices. London. Sage publication.

Hall y du Gay (comps) (1996). Cuestiones de identidad cultural. Buenos Aires-Madrid: Amorrortu.

Ibáñez, T. (1988) Ideologías de la Vida Cotidiana. Editorial Sendai, Barcelona. España.

Informe de la verdad (1993) De la Locura a la Esperanza: La Guerra de los Doce Años en El Salvador: Informe de la Comisión de la Verdad para El Salvador. Editorial Universitaria, Universidad de El Salvador, San Salvador.

IUDOP (2008) Encuesta de evaluación del año 2007 CONSULTA DE OPINIÓN PÚBLICA DE NOVIEMBRE DE 2007 Instituto Universitario de Opinión Pública Universidad Centroamericana "José Simeón Cañas" San Salvador, El Salvador. Enero de 2008

(2007) Boletín Los salvadoreños y salvadoreñas evalúan la situación del país a finales del 2007. Año XXII, N². Consultado en http://www.uca.edu.sv/publica/ iudop/boletines.htm\#2007

IUDOP, Ministerio de Gobernación, PNUD y CNSP (2005) La 
encuesta "La victimización y la percepción de seguridad en El Salvador en 2004" San Salvador

IUDOP y FUNDAUNGO (2002) La encuesta sobre la percepción de la seguridad ciudadana a nivel nacional, municipal y zonal. San Salvador

Jodelet, D. (2004) El otro su construcción, su conocimiento. En Valencia, Silvia (Coord) (2006) Representaciones sociales. Alteridad, epistemología y movimientos sociales. Guadalajara: Universidad de Guadalajara y Centro Universitario de Ciencias de la Salud.

(1993). El lado moral y afectivo de la historia. Psicología Política, 6, 53-72.

Jodelet y Guerrero (Coord.) (2000) Develando la cultura. Estudios en Representaciones Sociales. México : UNAM. Facultad de psicología

Lefebvre, Henri (2006) La presencia y la ausencia. Contribución a la teoría de las representaciones. Traduc. de Óscar Barahona. México: FCE

León. E. (2005) Sentido ajeno. Competencias ontológicas y otredad. Barcelona: CRIM/ Anthropos

Mora, Martín (2002). La teoría de las representaciones sociales de Serge Moscovici. Atenea Digital, 2. Disponible en http:// blues.uab.es/athenea/num2/ Mora.pdf
Moscovici, S. (1984). Psicología Social, I. y II Pensamiento y vida social: Psicología social y problemas sociales. Barcelona: PAIDOS.

Moscovici, Serge y Uribe Patiño (1997) Los referentes ocultos de la psicología política. México: UAM Iztapalapa.

Orfali, Birgitta (2002) Active Minorities and Social Representations: Two Theories, One Epistemology. Journal for the Theory of Social Behaviour. 32:4

Paicheler, Henri (1986).La epistemología del sentido común. En Moscovici, S. Psicología social II. Pensamiento y vida social. Psicología social y problemas sociales. Barcelona-Buenos Aires-México: Paidós.

Paz, O. (1970) Posdata. Siglo XXI: México

Perera, Maricela 2005 Tesis de Doctorado citada en Perera, A.C. Redes transnacionales, representaciones sociales y discurso religioso en Cuba revisado en bibliotecavirtual.clacso.org.ar/ ar/libros/cuba/cips/caudales06/ fscommand/27P13.pdf

Portillo, N., Gaborit, M., Cruz, J.M. (2005). Psicología social en la posguerra: teoría y aplicaciones desde El Salvador. San Salvador: UCA editores

Programa de Naciones Unidas para el Desarrollo (PNUD) (2006) Informe 262 Indicadores Munici- 
pales sobre Desarrollo Humano y Objetivos de Desarrollo del Milenio, San Salvador: PNUD.

Programa de las Naciones Unidas para el Desarrollo (PNUD) (2005). ¿Cuánto le cuesta la violencia a El Salvador? Cuadernos sobre Desarrollo Humano No. 4. San Salvador.

Raiter, Alejandro y otros (2002) Representaciones sociales. Eudeba: Buenos Aires

Reguillo, Rossana (2003) Ciudadano. Crónicas de la diversidad. Guadalajara: ITESO

(2003). Utopías urbanas. La disputa por la ciudad posible Escrito en Ciudades No.:60- Sección: Ensayo. Guadalajara: ITESO

Rodríguez, Tania (2003) El debate de las representaciones sociales en la psicología social Revista Relaciones. Invierno Vol. 24 No. 93 El Colegio de Michoacán. Zamora, México. pp. 51-80
Samayoa, S. (2003) El Salvador. La reforma pactada San Salvador: UCA editores.

Sarlo, B (2006) Tiempo pasado. Cultura de la memoria y giro subjetivo. Una discusión. Siglo XXI: México D.F.

Schutz y Luckmann (2003) Las estructuras del mundo de la vida. $1^{\text {a }}$ reim. En Castellano. Buenos Aires: Amorrortu

Wagner, W. (1989). Social representation and habitus - Some problems in relating psychological with sociological concepts. Paper presented at the 1st European Congress of Psychology, Amsterdam.

Waldman, P. (2006) El Estado anómico: Derecho, seguridad pública y vida cotidiana en América Latina. 2da edición revisada. Iberoameriacana Vervuert: Madrid 